\title{
Reintegración de la Fábrica a la Ciudad, a través del Parasitismo y la Regeneración Urbana
}

\author{
Reintegration of the Factory to the City, through the Parasitism and Urban Regeneration
}

Reintegração da Fábrica à Cidade, através do Parasitismo e Regeneração Urbana

\author{
Luis Felipe Andica Pérez \\ Arquitecto Universidad Gran Colombia, Armenia \\ MSc. Arquitectura y Urbanismo Universidad Católica de Pereira, Colombia. \\ Ifarquitecto23@gmail.com \\ (iD) https://orcid.org/0000-0002-9297-443X \\ Andrés Mauricio García Lozano \\ Arquitecto Universidad Gran Colombia, Armenia \\ Esp. en Paisajismo Universidad del Valle \\ MSc. Arquitectura y Urbanismo Universidad Católica de Pereira \\ agarcialozano@gmail.com \\ (iD) https://orcid.org/0000-0003-4924-6709
}

Recibido: Enero 14 de 2020
Aceptado: mayo 27 de 2020
Publicado: junio 4 de 2020

\section{RESUMEN}

El artículo responde a la pregunta: ¿Cómo reintegrar la Fábrica a un Sistema de Ciudad? Como lugar de estudio se estableció la Zona Industrial de La Tebaida, Quindío. La metodología parte de un análisis cualitativo del lugar y una búsqueda de herramientas que conceptualicen un modelo de transformación urbana. Se establecen los conceptos de Parasitismo y Regeneración Urbana, como instrumentos que permiten reinterpretar el espacio y función de la Fábrica en torno a las dinámicas urbanas. Los resultados determinan un modelo urbano conceptual, en el cual se recicla la Fábrica y se le otorga valor, permitiendo que haga parte del sistema vivo de ciudad.

Palabras clave: Regeneración Urbana; Parasitismo; Fábrica.

\begin{abstract}
The article answers the question: How to reinstate the Factory to a City System? The Industrial Zone of La Tebaida, Quindío was established as a place of study. The methodology starts from a qualitative analysis of the place and a search for tools that conceptualize an urban transformation model. The concepts of Parasitism and Urban Regeneration are established as instruments that allow reinterpreting the space and function of the Factory around urban dynamics. The results determine a conceptual urban model, in which the Factory is recycled and given value, allowing it to become part of the living city system.
\end{abstract}

Keywords: Urban Regeneration; Parasitism; Factory. 


\section{RESUMO}

O artigo responde à pergunta: Como restabelecer a fábrica em um sistema de cidades? A Zona Industrial de La Tebaida, Quindío, foi estabelecida como um local de estudo. A metodologia parte de uma análise qualitativa do local e da busca de ferramentas que conceitem um modelo de transformação urbana. Os conceitos de Parasitismo e Regeneração Urbana são estabelecidos, como instrumentos que permitem reinterpretar o espaço e a função da Fábrica em torno da dinâmica urbana. Os resultados determinam um modelo urbano conceitual, no qual a Fábrica é reciclada e valorizada, permitindo que ela se torne parte do sistema de cidades vivas.

Palavras-Chave: Regeneração Urbana; Parasitismo; Fábrica.

\section{INTRODUCCIÓN}

La Industrialización de las ciudades como fenómeno urbano, ha ocasionado diversos impactos en los territorios a través de la historia. La Fábrica y su taxonomía han sido insertadas en diversos modelos urbanos, creando discusiones desde la planeación y sus resultados en la práctica misma. Un ejemplo de ello es la planificación por zonificación de usos y el impacto de la Industria, a partir de este modelo urbano. Desde esta perspectiva, el presente artículo realiza un estudio de los problemas y condiciones de zonificar, dividir o fragmentar un territorio. Llevado a un area de estudio denominada como "Zona Industrial de La Tebaida, Quindío", la cual ejemplifica la particularidad del emplazamiento de la Fábrica y sus contradicciones en el desarrollo de la Ciudad.

Metodológicamente, este estudio se enmarca bajo un analisis cualitativo y una busqueda rigurosa de información, con el objetivo de brindar herramientas conceptuales, llevando a cabo un proceso de hipótesis y transformación de este espacio urbano. Se plantea la Regeneración Urbana asociada al Parasitismo, un concepto biológico, elevado a un terreno técnico y sensible como lo son la Arquitectura y el Urbanismo, haciendo una analogía que busca romper las barreras y estigmas que rodean a la Fábrica y su relación con la Ciudad.

La propuesta se desarrolla desde el diseño conceptual y la aplicabilidad en la noción de la Regeneración Urbana; el reciclaje juega un rol determinante, que no solo pretende un rescate de los elementos físicos sino del espíritu social implicito en el lugar. El Parasitismo, como complemento, configura una superposicion de usos mixtos, a través de nueva Arquitectura flexible y adaptable, que responde a un modelo urbano, práctico, funcional y compacto. En Arquitectura, el uso del espacio y la sinergia entre sus componentes, su impacto ambiental, social, cultural, económico y político, se enlaza directamente con el desarrollo del ser humano y su hábitat. Es fundamental repotenciar estos espacios productivos, que son vistos como objetos distantes y en dicotomia constante con su entorno. La reinterpretacion del lugar juega un papel vital en la propuesta conceptual que busca otra mirada en un contexto, que, por su virtud, debe jugar un rol dinámico y no estático en los procesos naturales de la vida urbana.

\section{METODOLOGÍA}

Metodológicamente, este trabajo se construye bajo una base cualitativa. Se delimitó un lugar concreto en el territorio, con las siguientes características: urbanizado, con uso Industrial, logístico, en un entorno cercano al casco urbano y con relevantes factores de análisis espaciales, funcionales y sociales. Se realizó un análisis histórico del lugar, determinando su origen, condiciones, estado actual y posibles detonantes para un Proyecto Estratégico. Además de una revisión sobre el rol de la Industria y su relación con la Ciudad en un panorama histórico, resaltando las variables más relevantes y su paralelismo con el lugar de estudio en La Tebaida, Quindío.

Para el desarrollo conceptual del Proyecto se establecieron dos herramientas teóricas principales: 1. El Parasitismo, desde la Biología, y su analogía aplicada conceptualmente a un proceso de reinterpretación espacial y funcional de piezas arquitectónicas. 2. La Regeneración Urbana como instrumento de planificación, aportando una estructura que define los ámbitos para una planificación del territorio, mucho más sensible con el lugar, interpretando el contexto y exponiendo 
su capacidad de evolución positiva, a partir del mismo. Fue necesario un estudio riguroso de la definición de los términos, para lograr un aporte fundamental en la reinterpretación espacial y sus principales características, con el fin de determinar un engranaje y postura holística, como respuesta a la problemática urbana planteada.

El resultado del estudio se concluye en una hipótesis proyectual que se desarrolla bajo un Manifiesto de visión como Proyecto. Se desarrollan estrategias urbanas, arquitectónicas, programas y factores, sobre el diseño urbano arquitectónico que se plantea como tipología de futuros desarrollos en otras zonas de similar condición urbana.

\section{LA FÁBRICA Y LA CIUDAD}

Las Zonas Industriales sin lugar a duda son áreas que han generado impactos en la configuración de Ciudad y Áreas Rurales Metropolitanas a lo largo de la historia y desde su existencia o establecimiento formal. Ponce y Martinez (2001) explican que la lógica capitalista, la relación entre los Empresarios Industriales y la Ciudad se establece sobre la base de ventajas comparativas que estos han encontrado en las aglomeraciones urbanas. De esta manera, se ha creado una relación necesaria y con intereses, al parecer recíprocos, en una primera instancia. Sin embargo, el desarrollo de los modelos ha producido impactos negativos que la Ciudad ha debido asumir en calidad de vida, afectaciones medio ambientales $y$, por supuesto, sociales.

El desarrollo económico que atraen las Fábricas es acompañado de lugares eminentemente funcionales. Se han establecido en centros de ciudad $y$, posteriormente, han sido desplazadas a lugares periurbanos, respondiendo a lógicas de mejores relaciones regionales y con el transporte. El impacto que producen las Fábricas en un entorno de ciudad, genera transformaciones sobre el espacio urbano. Lo que nos permite pensar en unos nuevos prinicpios ordenadores de la relación Industria y Ciudad.

La interacción entre la Industria y las Áreas Urbanas ha creado un paradigma, al pensar en una posible relación y cercanía entre usos productivos y su convivencia con otros usos en el mismo espacio.
Es importante entender que el diseño de estas grandes superficies se basa en infraestructura meramente en funcion de su uso. No permiten que la Ciudad infrinja sus bordes o cerramientos convirtiéndolos en islas, aun encontrándose en el interior de un centro urbano poblado.

Lo que se puede precisar es que el emplazamiento de la Industria hace parte de un fenómeno que ahora no solo interfiere en las Áreas Urbanas. Las zonas de transito metropolitano se han convertido en lugares idóneos para su desarrollo, lo que detona al mismo tiempo nuevos centros y focos con un tipo de urbanización especializada, que impacta directamente en el territorio y que se convierte y hace necesaria una planificación integral multiescalar para su correcto desarrollo.

\section{ENTENDER EL PARASITISMO}

El termino parásito procede del griego y significa "sentado al lado del alimento". La generalización biológica se debe a los médicos veterinarios romanos, que denominaron así a los animales que vivían y se alimentaban de otros (Sánchez, 2000). Ahora bien, el Parasitismo está compuesto de diferentes variables que lo definen; su origen, evolución y las adaptaciones que ha tenido en los diferentes ambiententes, especies o cuerpos. A partir de este panorama, se abordarán los elementos escenciales para el desarrollo de una analogía con los Procesos Urbano-Arquitectónicos que se plantean en este artículo.

El Parasitismo surge producto de una asociación que ha evolucionado gracias a la adaptación entre dos asociados; el parásito por un lado y el hospedador por otro. Al existir una relación conjunta entre dos organismos, se pueden construir relaciones cortas, pasajeras o largas en el tiempo. Según su duración, los parásitos pueden explotar, no solamente los materiales del otro socio, sino que, además, los otros tres bienes (procesos, trabajos y frutos del trabajo). Se plantea que, en la práctica, el sistema parásito-huésped es un sistema de fenotipos cruzados, ya que cada uno puede interferir en el territorio del otro, resultando balances negativos o positivos, según sea desde el organismo que provenga la intervención en el otro (Sánchez, 2000). 


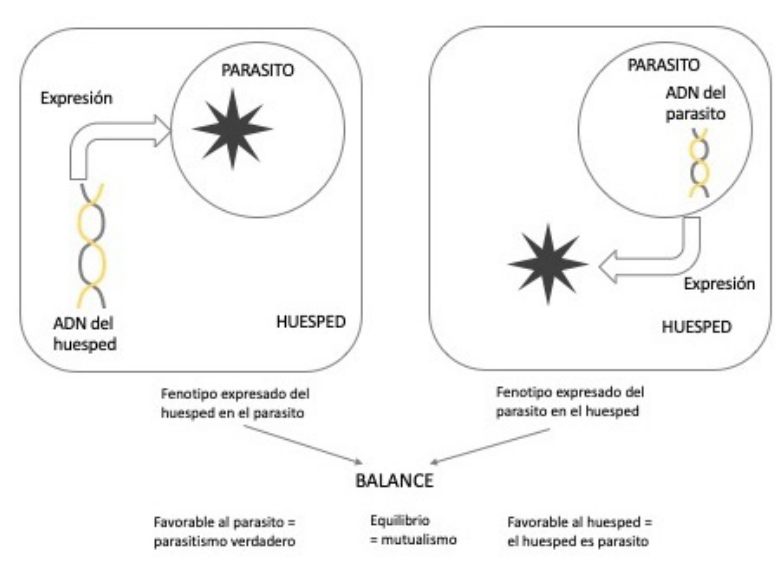

Figura 1. Balance y Resultado de Intercambio de Genes entre Parásito y Hospedador Fuente: Tolosa, Chiaretta y Lovera, 2006.

Este juego interactivo entre el parásito y el hospedador tiene dos consecuencias principales que se determinan como Parasitismo y Mutualismo, cada una cumpliendo un rol singular en esta asociacion. Primero, se define el Parasitismo, cuando la asociación es ventajosa nada más que para el parásito; se habla de Mutualismo cuando la asociación es ventajosa para cada uno de los dos socios. En este sentido el Mutualismo es una condición llamativa y pertinente, si se piensa en simbiosis. El interés de que existan diversos actores se construye con el fin de generar sinergias y beneficios, en lo posible recíprocos, entre los integrantes de un Sistema Urbano.

La tradición ha calificado al Mutualismo como una asociación con beneficios recíprocos; en realidad es, más bien, una asociación de Parasitismo recíproco, en que el huésped, a su vez, explota a sus parásitos (Sánchez, 2000). Las relaciones donde existen beneficios recíprocos se convierten en importantes, en la medida en que dos o más organismos puedan tener un desarrollo equilibrado. Esto nos lleva la siguiente analogía: un centro comercial requiere de una poblacion que lo visite y compre, que haga uso de sus espacios, siempre buscando un beneficio económico o de otro tipo. Al mismo tiempo, la personas que lo visitan se benefician de lo que este lugar les ofrece, bien sea ocio, alimentación, diversiones o simplemente compras. Debe existir un intercambio de genes, dinero, publicidad, promociones, siempre buscando interacción. De este modo, el Mutualismo puede verse reflejado en muchas situaciones de la vida urbana.
Finalmente, al definir los tipos de vida parasitaria, se logra una caracterización que nos lleva a identificar potenciales en aspectos de ubicación y tipos de relacionamiento. Los parásitos que viven en el interior del cuerpo, como Endoparásitos, y los que se asientan en las superficies externas, como Ectoparásitos Según el tiempo de contacto de los parásitos obligados con sus hospederos, pueden clasificarse en temporales, periódicos y permanentes (Tolosa, Chiaretta y Lovera, 2006).

\section{REGENERACIÓN URBANA}

En la actualidad, existen diversos instrumentos de Planificación urbana para el abordaje de problemáticas en el territorio. El caso que nos presenta la Zona Industrial de La Tebaida, Quindío. Instrumentos como la Renovación Urbana, desde la Planificación, tienen como fin la desapracion total de lo que existe en un área determinada. Para construir un lugar nuevo, a lo mejor un nuevo espacio público o nueva Arquitectura. Cuando se habla de desaparición total es, no solamente, la intervención física del lugar. Los Espacios Urbanos, más allá de tener edificios, calles, o plazas, tienen memoria, anécdotas que contar, raíces y arraigo. Esto también desaparece cuando se interviene el territorio de una forma a lo mejor atropellante y soez.

Ahora bien, regenerar es llevar algo deteriorado a un estado de vitalidad, es restablecer las células de un organismo defectuoso o alterado, si se aborda desde una mirada biológica. Reciclar un organismo o elemento, que se encuentre en un estado crítico, afectado por otros o su por propia atmósfera. Jones y Evans (2013) describen que la "Regeneración" surgió durante la década de 1980, e indica que el proceso se trata de algo más que simplemente la demolición y la reconstrucción. Furbey y Macey (2005) explican que «Regeneración» en latín significa "renacimiento», y encarna una serie de valores judeocristianos acerca de nacer de nuevo.

Como lo menciona Remesar (2012), la Regeneración expone dos caracteristicas claves en el proceso de transformacion que será llevado a cabo en la Fábrica en La Tebaida, Quindío.

Desde el punto de vista urbanístico son procesos no expansivos, es decir, que no buscan incrementar el suelo urbanizable. 
Tienen una finalidad común, un objetivo principal: se centran en la resolución de problemas urbanos, en áreas degradadas y/o marginales, a partir de un cambio o transformación urbana, que no tiene por qué ser solo física, sino que también puede ser social, económica, ambiental, cultural, etc.

La estructura de un proceso regenerativo debe abordar los siguientes ámbitos: físico, social, político, ambiental y cultural. Además, para una Planificación Estratégica se plantea; "La exigencia de abarcar diversas escalas territoriales y administrativas (barrio, ciudad, área metropolitana, región, país, etc.), así como por dar cabida a los múltiples actores que forman parte, directa o indirectamente, del proceso de transformación (Remesar, 2012). La Tebaida, Quindío, como Municipio, presenta factores de degradacion y declive en aspectos sociales, de trabajo y de infraestructura física. Sin embargo, cuenta, asimismo, con grandes posibilidades para un desarrollo integral, si logra la conexión adecuada entre los actores, dimensiones y detonantes estrategicos. La ubicación del Municipio y su conexión regional, lo hace, desde su centralidad, un encuentro de caminos, no solo a nivel nacional, sino también intermunicipal. La población joven y su extensión de área urbana de $1,5 \mathrm{~km}^{2}$ la hacen una ciudad pequeña y con condiciones de potencial desarrollo.

La Regeneración, como herramienta de desarrollo urbano, plantea algunos patrones que potencian su sistema y se describen en la Tabla 1.

Tabla 1. Patrones que potencian la Regeneración como herramienta de desarrollo urbano.

a. Desarrollar las potencialidades autóctonas del área relacionada con la mejora del stock físico, esto es: edificios, espacio público, infraestructuras, etc., buscando generar una atracción de empresas y aumento de la actividad económica del territorio.

b. Aumentar la inversión en nuevas formas de actividad vinculadas al sector de servicios y ocio. Es decir, crear nuevas infraestructuras relevantes que sean capaces de atraer visitantes autóctonos, como turistas. Un ejemplo tradicional son los museos de arte contemporáneo en zonas degradadas.

c. Ofrecer una mejora de la ciudad, en general, y, específicamente, dotándola de un carácter específico que la diferencia de otras ciudades. El ejemplo de Barcelona, con su arte público, que es reconocido a nivel mundial.

d. Realizar un proceso integral de Regeneración Urbana, basado en la integración y participación de los residentes en el proceso, para lograr, no sólo una mejora física del territorio, sino, a su vez, aprovechar la dinámica de cambio para lograr una mejora social de los residentes.

Fuente: Remesar, 2012.
Si se anliza esta guia de varibles proyectuales, se deduce que todo converge en un modelo de desarrollo urbano sostenible, que incentiva el aprovechamiento de recurosos autoctonos, y nuevas fuentes de economia. Convirtiendolo en un sistema de Planificación con capacidad de permear en diversos campos de la vida urbana tanto físicos como sociales y politicos.

Por otra parte, Batty (2012) plantea que la Regeneración es un proceso que debe ser auto regenerativo, una característica clave de los sistemas que se regeneran a sí mismo es que lo hacen espontáneamente. Adicionalmente plantea un modelo el cual, determina la importancia de localizar nodos estratégicos en áreas de posible Regeneración. El truco para la planificación urbana es identificar los puntos clave donde un pequeño cambio puede conducir espontáneamente a un cambio masivo positivo (Batty, 2012) Lo que convierte el lugar de estudio; la Zona Industrial, en un terreno apto y de singular condición para llevar a cabo un proceso regenerativo como se observará más adelante.

\section{CONTEXTO Y LUGAR}

La Tebaida es uno de los doce Municipios del departamento de Quindío, el cual ha sido llamado a ser un centro de acopio, logístico e Industrial de la región. su ubicación estratégica, su cercanía al aeropuerto de Armenia, su estrecha relación con la Vía Panamericana y sobre todo por ser un paso obligado entre la capital del país y el puerto de buenaventura motivaron a la construcción de una Zona Industrial y logística en el año 1993, siendo un área aproximada de 39 hectáreas donde emplaza un conjunto de Fábricas y bodegas. Esta área se proyectó y se visualizó como un impulsor económico no solo en La Tebaida si no para la región. Por distintos motivos en la actualidad no se a cumplido con este objetivo y sumado a las problemáticas generales de las Zonas Industriales cuya relación con la Ciudad es relegada desde su planificación y que ya en su función física no tienen la interpretación y la adaptabilidad a un territorio urbano. 


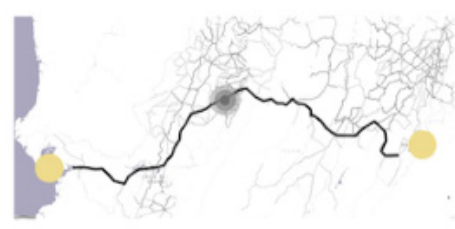

Conexión
Pacífico- centro del pais

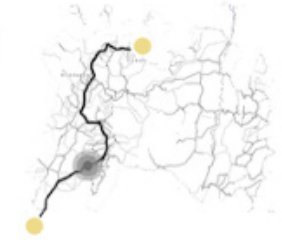

Conexión Regional Caldas-Valle

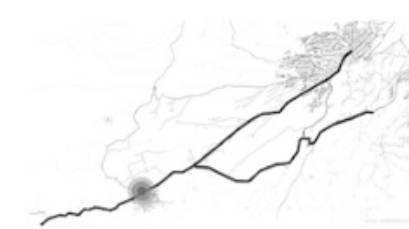

Conexión con Armenia capital del Quindío

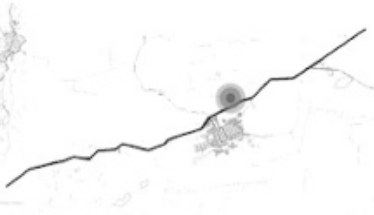

La Tebaida y la zona industrial

Figura 2. Esquema de localizacion y relaciones multiescalares de la Zona Industrial La Tebaida, Quindío. Fuente: Elaboracion propia

Para entrar a un análisis de las características del Municipio, es necesario decir que el futuro del país se ha planeado de acuerdo con la necesidad de mejorar las vías terrestres y ferroviarias. Dos casos concretos son: el túnel de la línea; que tendrá incidencia con el Municipio de La Tebaida para comunicar a Bogotá con el pacífico colombiano, y la Vía Panamericana que tiene una alta importancia en las actividades del país, departamento y Municipio, y una incidencia directa con este Proyecto. En este contexto el Departamento del Quindío con su posición estratégica entre el occidente y centro del país, es una región que jugará un papel fundamental en torno a la conectividad, comunicaciones y valor agregado en el transporte y la logística de carga. (Gobernación del Quindío, 2011, p. 11 - 15).

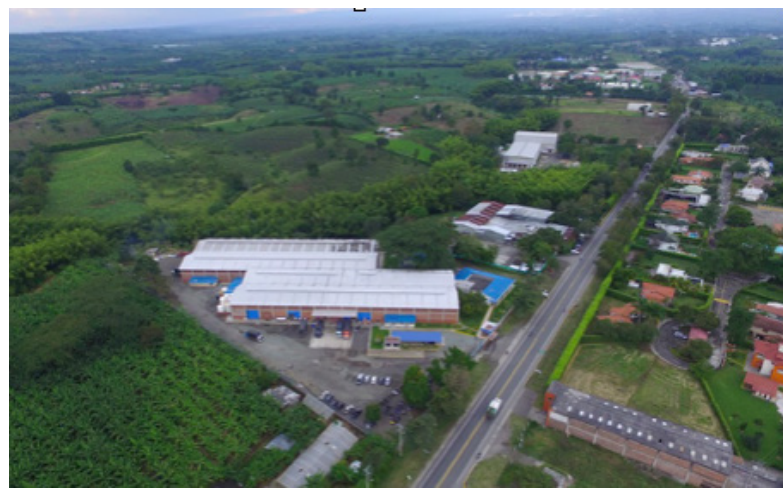

Figura 3. Fotografía aérea, fragmentación Zona Industrial y zona urbana por medio de via rutanacional 44

Fuente: Berhlan Colombia, https://berhlan.com/

Adentrando en un contexto urbano, la Zona Industrial se emplaza sobre la Vía Panamericana ruta nacional 44 . Via a que su vez, fractura una posible interaccion entre el casco urbano y el area llamada productiva. Sin embargo, no es la única fractura que se analiza en el lugar. El diseño de las Fábricas y Bodegas son tradicionales; elementos de Arquitectura pesada, ortogonal y de alturas máximas de $12 \mathrm{~m}$, artefactos que se encierran en si mismos. Modelos que podrían emplazarse en otro territorio sin causar igual ningun efecto espacial positivo. Carentes de espacio público y poca respuesta urbana a la Ciudad. A pesar de ser una area destinada para procesos Industriales y logísticos, no tienen una Planificación de Estructura Vial idónea, alimentan su transporte desde la misma via nacional lo que incurre en problemas de movilidad haciendo parte de un fenomeno negativo sobre este importante eje vial.
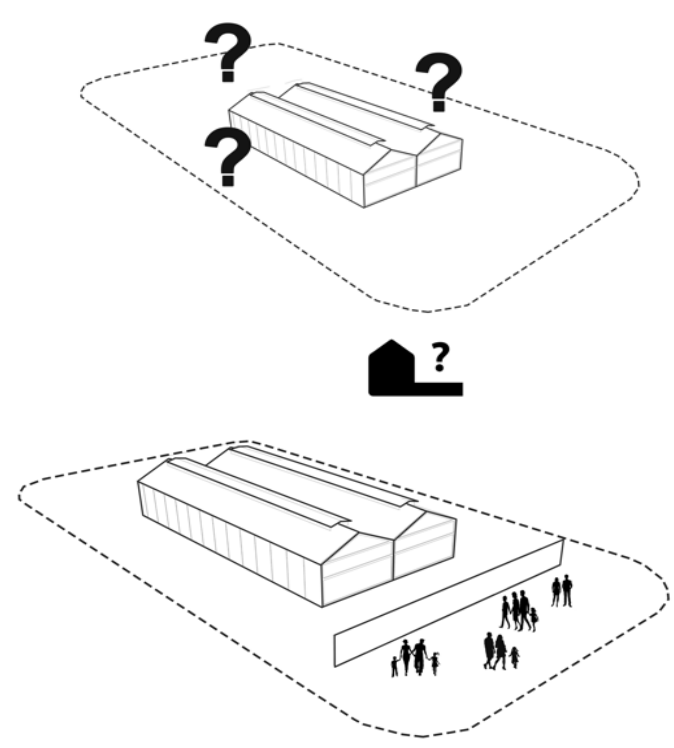

Figura 4. Esquemas. 1 Identificación de la Fábrica como barrera espacial, 2. Desaprovechamiento del suelo, uso inapropiado en Parqueaderos y Áreas de Carga y Descargue. Fuente: Elaboración propia. 
La población de La Tebaida revela un incremento por encima del $100 \%$ en 20 años. Antes del terremoto de 1999 del eje cafetero, La Tebaida contaba con una población de 20.000 habitantes, hoy la población se encuentra en 44.000 habitantes aproximadamente. Además, La Tebaida es una población receptora de población migrante desde el episodio natural, siendo esta una característica que puede ser vista como oportunidad.

El índice de pobreza multidimensional medido en el año 2005 indicó que el $53 \%$ de la población se encontraba en esta condición, 11 puntos porcentuales por encima de la medición para el Departamento del Quindío. Esta situación revela el bajo impacto que ha tenido la Zona Industrial en el desarrollo del Municipio y su población. A partir del análisis cualitativo con énfasis en las condiciones físicas del lugar. Se corrobora que este es un espacio con fuertes problemáticas de desconexión y falto de reconocimiento de sus propios valores. Sin embargo, no cabe de dudas que sus bondades son la plataforma para la transformación de un nuevo panorama para esta Zona Industrial. Ahora bien, se deberá responder a la pregunta de ¿cómo es posible reintegrar la Fábrica a un sistema de Ciudad, a sus dinámicas, tanto físicas, como sociales con el fin de un desarrollo urbano compacto, sostenible y más humano?

A continuación, en la Tabla 2. se presenta una síntesis de las problemáticas, oportunidades y estrategias identificadas como resultado de análisis.

\section{LA FÁBRICA COMO UN ECOSISTEMA URBANO}

Se plantea como hipótesis la reintegración de la Fábrica a partir del Parasitismo y la Regeneración Urbana. Enmarcado en un modelo de diseño teórico conceptual, como propuesta urbana arquitectónica sobre el caso de la Fábrica Berhlan de Colombia, componente urbano que servirá como modelo de estudio para la aplicabilidad de estrategias multidimensionales.

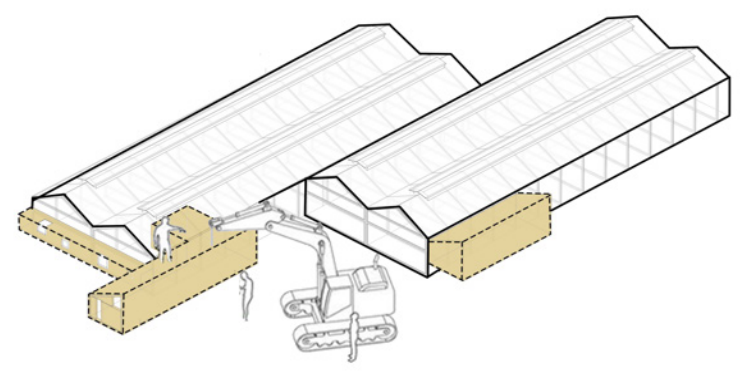

Figura 5. Hipótesis, nueva interpretación y aprovechamiento de la Fábrica.

Fuente: Elaboración propia

Berhlan de colombia es una empresa activa que hace parte de la configuración actual de la Zona Industrial de La Tebaida. Su producción se basa en productos de aseo, jabones, detergentes, entre otros. Genera 400 empleos para el Municipio, convirtiéndose en una importante fuente de trabajo. Está compuesta de cuatro naves principales

Tabla 2. Síntesis del Análisis

\begin{tabular}{|c|c|c|}
\hline e. Problema & f. Oportunidad & g. Estrategia \\
\hline $\begin{array}{l}\text { h. Lugar sin atractivos para nuevas } \\
\text { Industrias }\end{array}$ & $\begin{array}{l}\text { i. Localización estratégica, clima cálido, } \\
\text { suelos productivos }\end{array}$ & $\begin{array}{c}\text { j. Conectividad de transportes: aéreo, férreo } \\
\text { y terrestre. Vivienda, estadías. }\end{array}$ \\
\hline k. Usos mono función & $\begin{array}{l}\text { I. Re integración de la Fábrica con } \\
\text { yuxtaposición de nuevos usos del suelo }\end{array}$ & $\begin{array}{l}\text { m. Compatibilidad de usos para creación de } \\
\text { sinergias }\end{array}$ \\
\hline $\begin{array}{l}\text { n. Fragmentación urbana por Vía } \\
\text { Panamericana }\end{array}$ & $\begin{array}{l}\text { o. Transversalidad como integración de } \\
\text { casco urbano y Zona Industrial }\end{array}$ & $\begin{array}{l}\text { p. Comunicación y crecimiento urbano } \\
\text { inteligente, aprovechamiento del eje vial }\end{array}$ \\
\hline $\begin{array}{l}\text { q. Fábricas barreras, exceso de culatas sin } \\
\text { función }\end{array}$ & $\begin{array}{l}\text { r. Aprovechamiento de culatas para adición } \\
\text { de nueva Arquitectura }\end{array}$ & $\begin{array}{l}\text { s. Parasitismo como modelo arquitectónico } \\
\text { de adición }\end{array}$ \\
\hline t. Alto índice de población joven & $\begin{array}{c}\text { u. Alta demanda de población autóctona } \\
\text { como posibilidad de educación y } \\
\text { expectativas laborales }\end{array}$ & $\begin{array}{l}\text { v. Centros educativos, aprovechamiento } \\
\text { rural }\end{array}$ \\
\hline
\end{tabular}

Fuente: Elaboración Propia 
perpendiculares a la Vía Panamericana. Su Arquitectura se conforma de una cubierta a dos aguas y sus fachadas lisas en ladrillo visto. El diseño se desenvuelve en una estructura aporticada, que permite tener luces amplias para generar que su espacio interior sea totalmente útil y sin columnas centrales. Este tipo de hangares es muy común en Fábricas de Industria de Tipo Medio. En su contexto contiene vías para el acceso de vehiculos pesados, zonas de carga y desargue, parqueaderos. Posee un cerramiento que colinda paralelamente con la Vía Panamericana. No existe ningun medio de comunicacion peatonal o vehicular entre esta Fábrica y la Ciudad, lo que es sumamente peligroso para la poblacion trabajdora que transita diariamente en un cruce sobre una vía de carácter nacional. El lugar de las Fábricas es un polígono meramente para el trabajo y esto produce el valor de una nueva reinterpretacion (Figura 6).

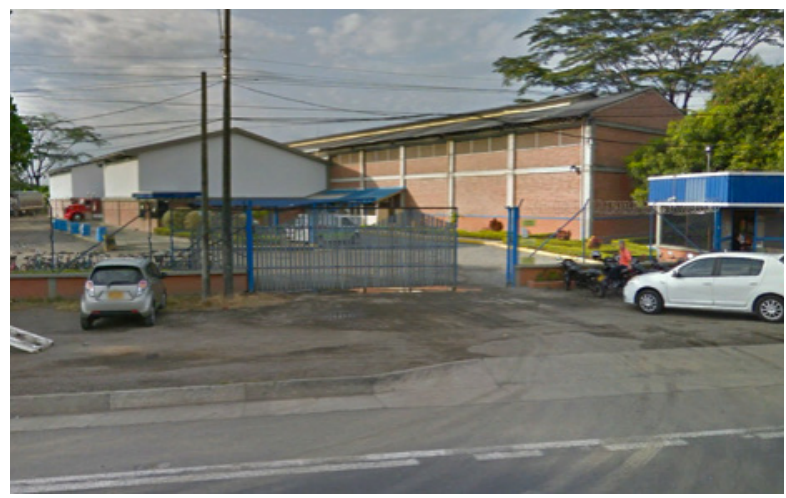

Figura 6. Fábrica Berhlan de Colombia, y su comportamiento en relación a su entorno. Fuente: Google Maps.
Debido a estas condiciones se enfrentará una problemática que es posible de solucionar si se piensa en respuestas integrales y no solo en escenarios especificos. La Regeneración Urbana, como lo menciona Batty (2012) es bastante sencillo de entender, concentrándose en tierras previamente desarrolladas en Áreas Urbanas para generar crecimiento. Las Ciudades de hoy y la Globalidad deben entender que las dinámicas urbanas son cada vez más cambiantes. Los espacios cada vez requieren de un mayor dinamismo, capacidad de cambios sin afectación de su estructura contenedora. Las Ciudades cambian continuamente a medida que las personas y sus actividades responden sin cesar a las circunstancias cambiantes de movimiento, ubicaciones, el uso de edificios y las preferencias sociales (Batty, 2012). Desde esta óptica la Fábrica Berhlan y su condición se convierte en un elemento urbano útil para el desarrollo de un Proceso de Regeneración. La Fábrica, a pesar de presentar dificultades urbanísticas, se convertirá en captor de nuevas mutaciones urbanas, sin perder su identidad física y productiva actual.

Los usos de suelo y sus dinámicas juegan un papel vital en la creación de una nueva atmósfera urbana. La clave para valorar la Regeneración Urbana es desarrollar una serie de escenarios en los que conectemos nuevos trabajos, hogares, tiendas y enlaces de transporte en el área (Batty, 2012). Se plantea que los factores que expone el sistema regenerativo crean la necesidad de trasladar nuevos usos a la Fábrica. Nuevas dinámicas donde se conformen ecosistemas urbanos y enlaces con la red física y ecológica de Ciudad. Se plantea desde un Manifiesto, una serie de patrones que brindarán una respuesta holística a las problemáticas que presente este territorio particular (Figura 7).

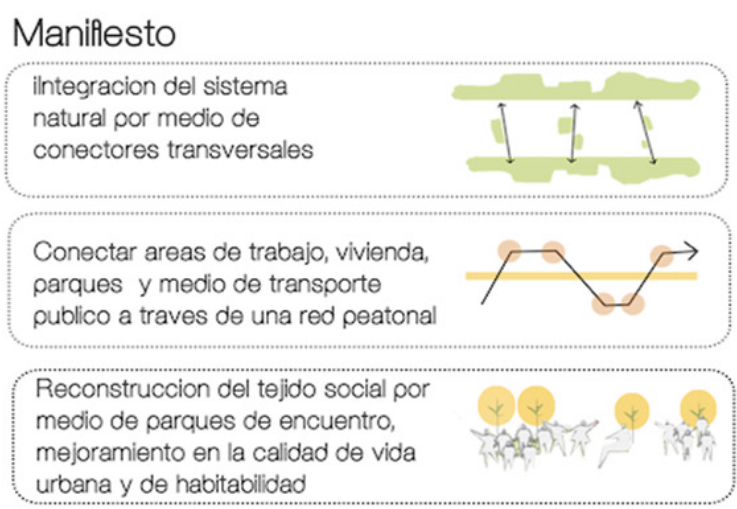

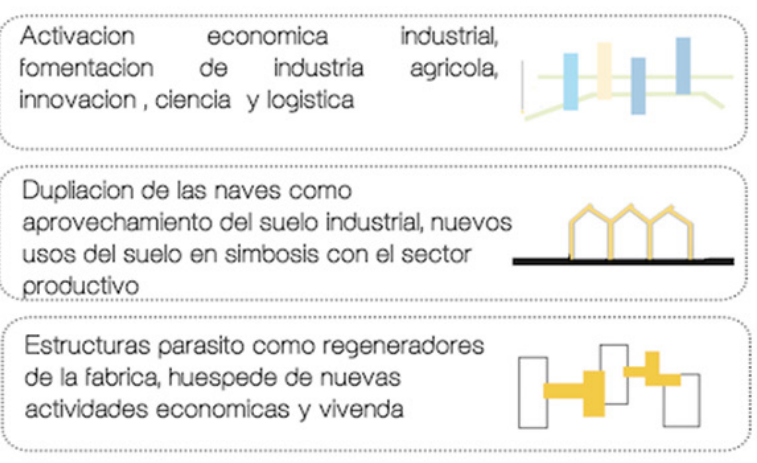

Figura 7. Manifiesto hipótesis proyectual. Fuente: Elaboración propia 
El Manifiesto traslada la discusión a una pregunta principal: ¿Cómo incluir nuevos usos del suelo a un sistema de Fábrica, ocupando su área, arquitectura y entorno espacial? Pues bien, en el Parasitismo biológico, como su definición lo precisa, se requiere de dos organismos: un "parásito" y un hospedador. En este caso la Fábrica Berhlan se convierte en el hospedador al poseer la energía y el cuerpo para ser receptor del "parásito", que, en este caso, se plantea desde la plasticidad de tipologías arquitectónicas, que al ser adheridas estratégicamente a las fachadas logran un aprovechamiento espacial y una inclusión de nuevas dinámicas a partir de estas nuevas plataformas flotantes. Ahora, esta relación no esta tan sencilla si se entiende que la Fábrica cumple con una variedad de proceso para su funcionamiento. La implementación de este modelo dependerá de una reconfiguración espacial tanto de la Fábrica, como de su entorno, vías de acceso y relación espacial interna (Figura 8 y 9 ).

Una vez producido un nuevo ambiente y reinterpretación especial a través de la adicción de nuevas piezas, el "Parasitismo" debe generar un efecto aún más profundo, para llevar a cabo un sistema polivalente. La condición de mutuación - Parasitismo recíproco al producir un efecto simbiótico, construyen una analogía con la Arquitectura a partir de programas y usos que logran una interacción con las demás actividades del lugar. En esta misma corriente se plantean posibilidades de una vida más humana y abierta a las dinámicas urbanas. Bohigas (2004) plantea que, si una Ciudad ha de ser un sistema de vida colectiva y un instrumento de información y comunicación, que utilice incluso las ventajas del azar, es necesario que el ciudadano tropiece constantemente con acontecimientos diversos, $y$, sobre todo, es indispensable que ningún ciudadano viva en un gueto, aunque este sea un gueto funcional. En este sentido, el Proyecto plantea reabrirse a la Ciudad, permitiendo todo tipo de accidentes urbanos a favor de una mejor calidad de vida urbana y de un constante intercambio y relacionamiento social.

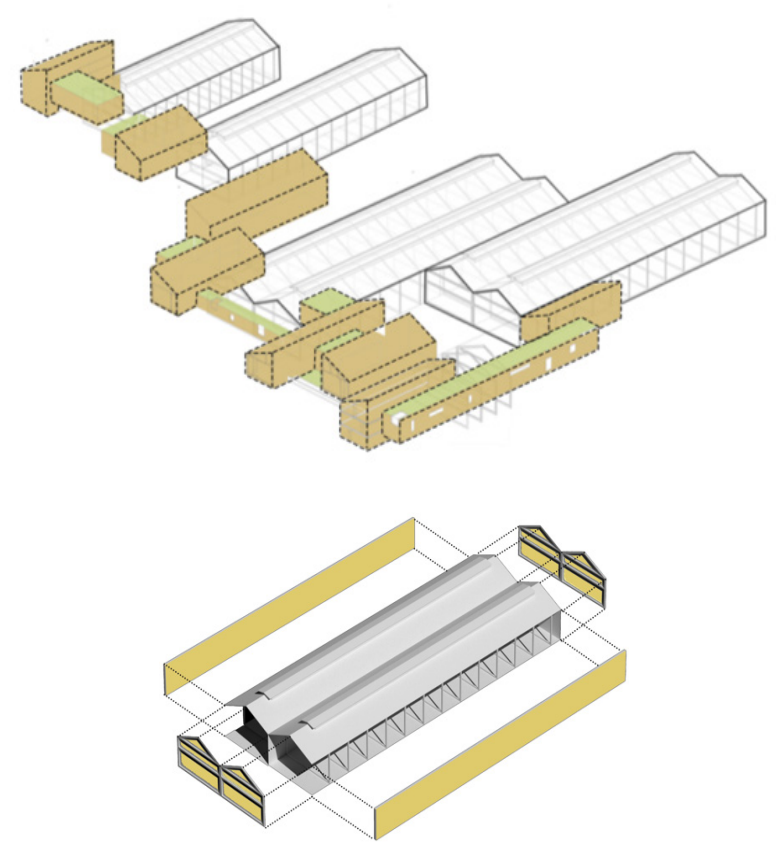

Figura 8. Fachadas de la Fábrica como oportunidad y tipologías de Parasitismo como Arquitectura adherida en fachadas.

Fuente: Elaboración propia

Ahora bien, es fundamental interpretar el lugar para proponer nuevas funciones. Batty (2012) plantea la combinación correcta de actividades, plantar semillas que conduzcan a la Regeneración atrayendo actividades relacionadas debido a su evidente sinergia. En ese sentido, se plantean usos que no solo sean compatibles con la Fábrica, sino también que entren en una búsqueda intensa por desarrollar nuevos ambientes, nuevas conexiones y una vida urbana diurna y nocturna. Los nuevos usos que se plantean son; comercio, vivienda, oficinas, hoteles, Industria, educación e innovación, complementados con parques, áreas verdes y nuevas zonas productivas de carácter agrícola (Figura 10).

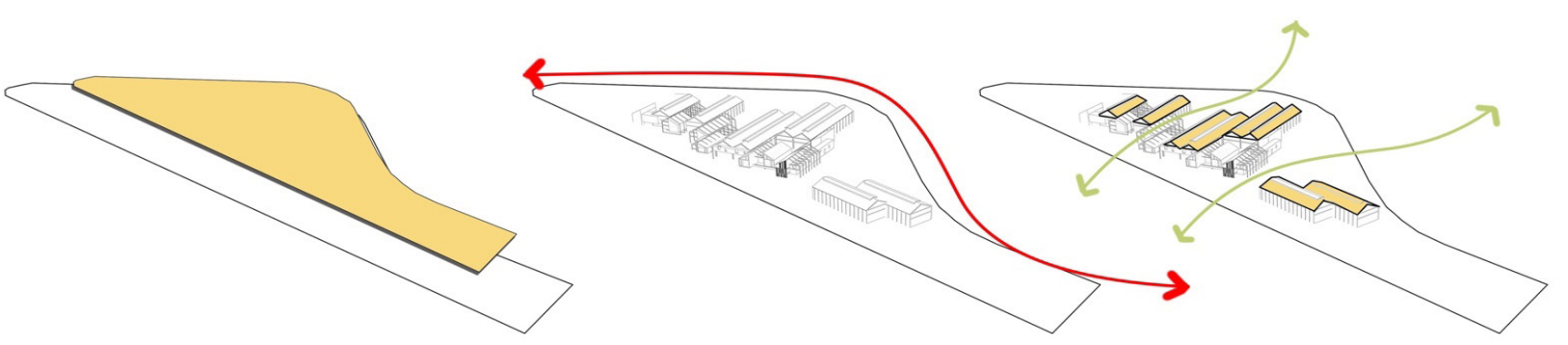

Figura 9. Reconfiguración vial, nueva vía posterior para uso logístico, lo que permite una fachada principal abierta al espacio público y actividades urbanas.

Fuente: Elaboración propia 
CAFÉ

investigacion PRODUCCIÓN OFICINAS C A R G A

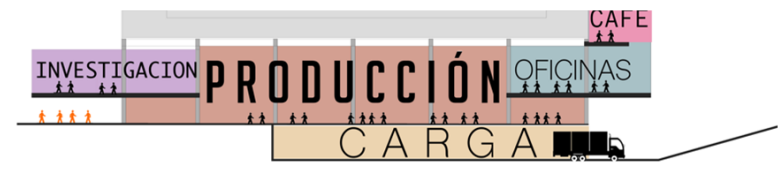

Figura 10. Programa vertical de Fábrica, con su uso principal productivo y los nuevos usos en simbiosis.

Fuente: Elaboración propia
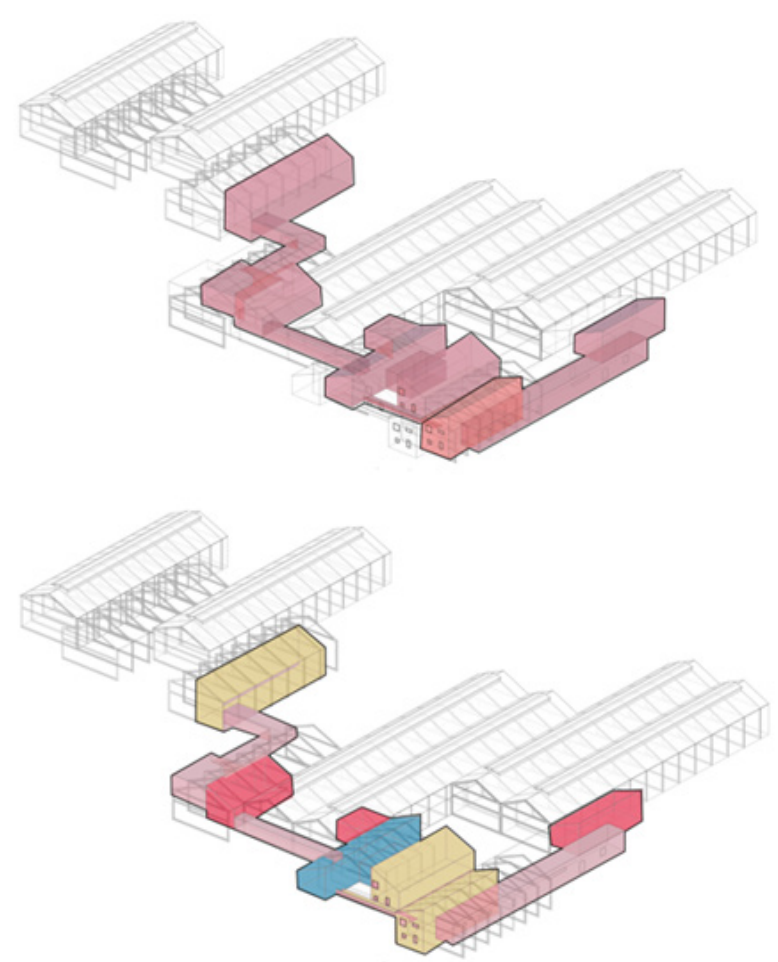

Figura 11. Superposición de usos sobre sistema de Fábrica.

Fuente: Elaboración propia

En la Arquitectura los modelos no son una respuesta idónea al pensar en Lugar y Proyecto. Sin embargo, se proponen prototipos volumétricos como una respuesta flexible al espacio y su condición, con capacidad de adaptabilidad, según la Arquitectura de la Fábrica y su relación interior exterior. Los prototipos se proponen como parte de un catálogo para su uso pertinente. Su función es hacer que su relación con el vecino juegue un rol pasivo o de actividades constantes; en el caso que propone el Parasitismo — donde los parásitos internos se denominan Endoparásitos; y los externos, Ectoparásitos-, la Arquitectura, en el ejercicio planteado, rompe la concepción del parásito en un único lugar establecido. El juego de volumetrías posee un vinculo entre interior y exterior, en muchos de los casos, lo que lo define en un terreno intermedio. En el caso de la Fábrica Berhlan se desarrolla un modelo intervenido por parásitos mixtos, que se emplazan y abrazan la Fábrica proponiendo un nuevo desarrollo espacial y funcional, con interacción externa e interna con la estructura existente (Figura 12).

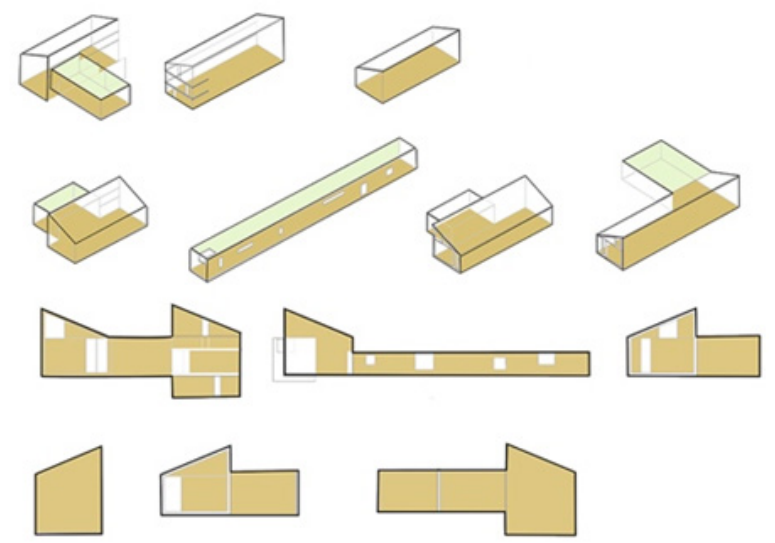

Figura 12. Tipologías Endoparásito y Ectoparásito como respuesta a la relación Fábrica y Entorno. Fuente: Elaboración propia

Ahora, ¿cómo se puede explotar la nueva condición espacial y de usos para llevarlo a un terreno más extenso? Según el planteamiento de Batty (2012) es necesario encontrar formas de plantar semillas que no caigan en terreno pedregoso. Se identifica un motivo más para proponer el "Parasitismo" como semilla en el caso de la Fábrica analizada, pues el terreno usado presenta unas características superficialmente pedregosas, pero que, estudiado en detalle, presenta las condiciones necesarias para dar frutos. Lo realmente fuerte que se logra extraer de esta propuesta de semilla, es que la Regeneración pueda evolucionar espontáneamente, a partir de localizar y reinventar zonas estratégicas que, finalmente, se terminen por reproducir, generando una Regeneración exitosa (Figura 13). 


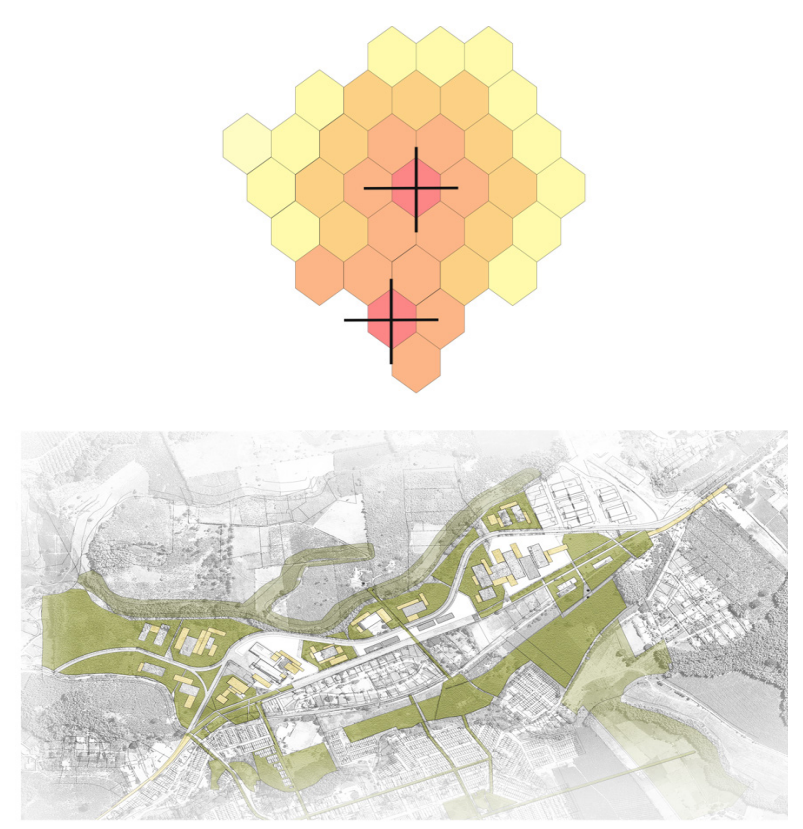

Figura 13. Sistema de Semilla en Fábricas de la Zona Industrial de La Tebaida, Quindío.

Fuente: Batty, 2012.

Será un reto lograr la Regeneración Urbana, porque su apuesta, como objetivo principal, dependerá de factores con baja maniobrabilidad, pues, se entiende que no dependerá únicamente de la puesta en marcha de la estrategia planteada y diseñada. No se trata únicamente de usar el Parasitismo para darle nuevos usos a la Fábrica; será ese mecanismo esencial para la promoción de un ideario espacial transformado y por transformarse. Se trata de impulsar una nueva concepción del espacio a todo un territorio con características particulares en un marco regional, departamental y municipal, que comprenda de antemano las potencialidades que posee para darle un giro a un espacio que terminará siendo el eje articulador de la Regeneración Urbana propuesta.

El proceso regenerativo tendrá como principio la congruenciadediversosactores. No podemosdefinir un proceso de Regeneración cuando el Proyecto no se construye en base de una planificación mancomunada. De esta manera, las estrategias que se plantean son de carácter arquitectónico, urbano y con impacto de conectividad regional y nacional, lo que hace necesario involucrar entidades privadas, gubernamentales, lideres comunales, la academia y la población civil en general. Con lo cual, se construye un escenario incluyente en el proceso de planificación (Figura 14).

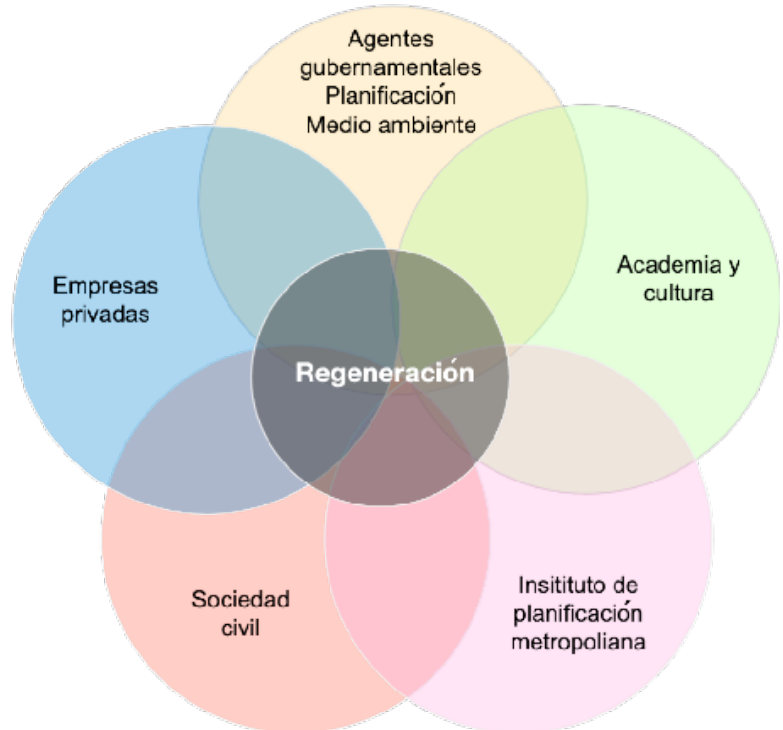

Figura 14. Mapa de actores directos en el proceso de Regeneración de la Zona Industrial La Tebaida. Fuente: Elaboración propia

La ubicación estratégica de este lugar hace que el Proyecto pueda sobresalir en otros ámbitos y condiciones de mayor escala, respondiendo principalmente a la conectividad con los transportes decarga terrestre, pormedio dela Vía Panamericana; aérea, desde el Aeropuerto Internacional Edén; y férrea, desde la línea proveniente del Pacifico y la cual tiene arribo a la Zona de Fábricas. Esta condición se potencia y se entrelaza en el nuevo ecosistema de la Fábrica, donde ya no se configura una zona netamente Industrial y Logística, sino un solo componente integral de Ciudad, donde la producción, a partir de la Industria, hace parte de un sistema (Figura 15 y 16).

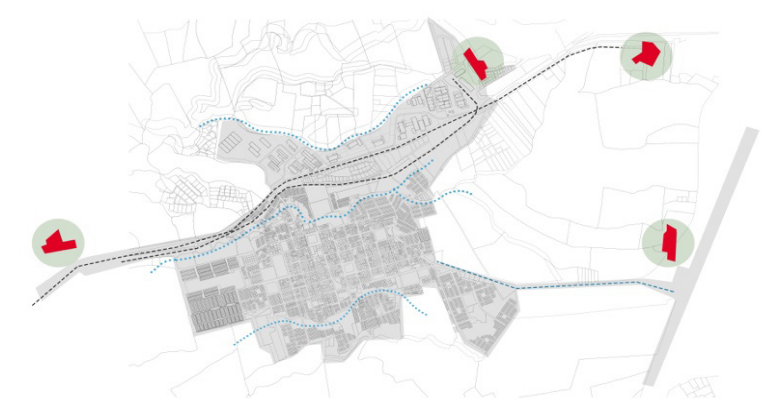

Figura 15. Estrategias de Movilidad de Transporte, conexión Aeropuerto, Vía Férrea y Vía Terrestre. Fuente: Elaboración propia 

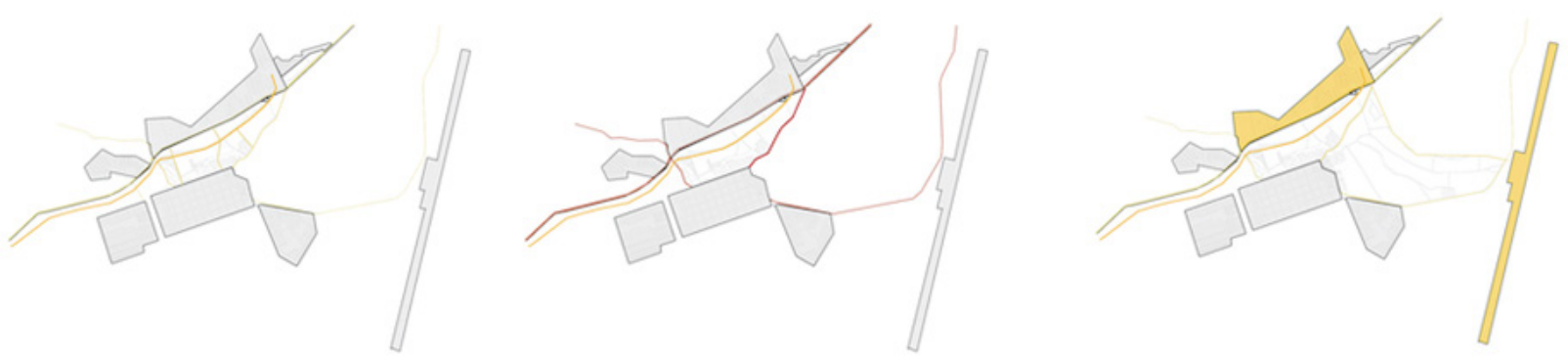

Figura 16. Conexiónes Urbanas de Zona Industrial con Aeropuerto, Casco Urbano y Vías Principales.

Fuente: Elaboracion propia

La necesidad de que la población del Municipio transforme su relación con el espacio público $y$, de este modo, con la manera de trasladarse de un lugar a otro, crea la oportunidad de generar un entorno propicio, que integre las dinámicas actuales y las propuestas. El espacio público como elemento que une socialmente las condiciones de la Ciudad, entra como herramienta estrategia, a hacer parte de la integración de Ciudad y Zona Industrial. En este caso generando transversalidad y rompiendo con la linealidad longitudinal que el trazado urbano ha compuesto a través del tiempo (Figura 17).

La respuesta a problemáticas urbanas, generalmente tiende en ir en un orden de planificación de escala macro a escala micro. Este proceso de restructuración de la Fábrica y su propósito de reintegrarla a la Ciudad, es un sistema que nace desde una solución del lugar, exactamente de la Fábrica como pieza. Sin desconocer las bondades y la interacción multiescalar, que se hace necesaria en un espacio logístico y productivo.
Se crea un desarrollo que permea los aspectos no solo físicos y tangibles, como vías, espacio público, corredores ambientales, infraestructura entre otros, sino a favor de una planificación pensada desde y para el ser humano, y sus necesidades directas. El poder trabajar, recorrer ambientes confortables, tener vivienda, y además la posibilidad de futuras poblaciones provenientes a una zona atractiva para trabajar vivir, hacen de la Regeneración un complemente favorable al planteamiento parasitario (Figura 18).

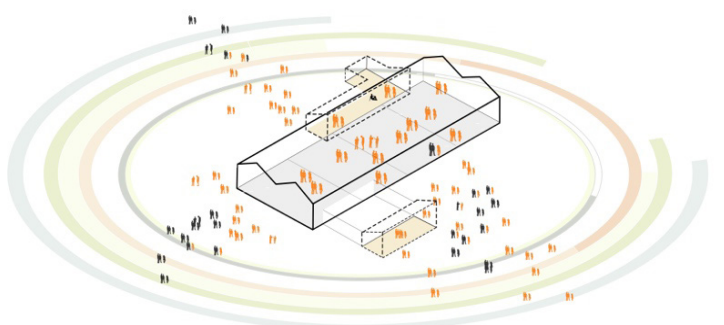

Figura 18. Intención de Sinergia Social a través de Regeneración de la Fábrica. Fuente: Elaboración propia
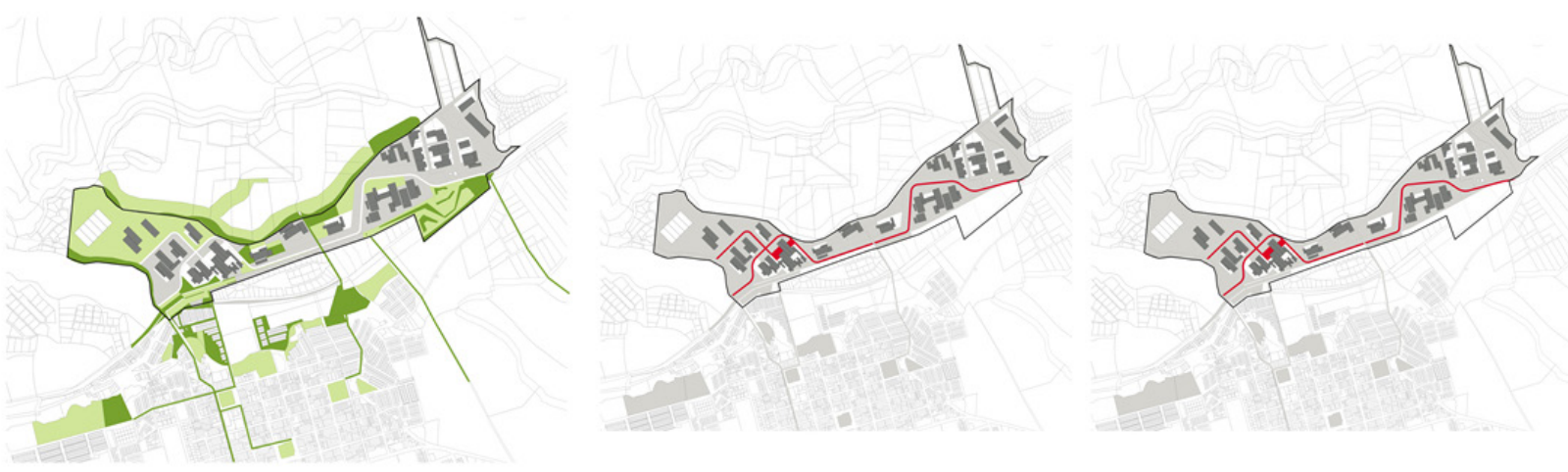

Figura 17. Estrategias Urbanas, corredores verdes transversales, nueva configuración vial Zona Industrial y plataforma de espacio público

Fuente: Elaboracion propia 
Los procesos de Transformación Urbana deben ser planificados bajo parámetros regidos por el lugar y todas las cosas que suceden a su alrededor. Al enfrentarse a un proceso de intervención, se deberá evaluar cada uno de los componentes y ámbitos físicos y sociales. Cuando se abordó la problemática en la Zona Industrial de La Tebaida, nunca se pensó en una renovación u otro proyecto distinto a lo que está establecido como Zona Industrial. A través de un análisis consciente y holístico, se determinó potenciar las Fábricas a partir de conceptos, a lo mejor utópicos para la realidad urbana de estos espacios. Pero que, a nuestro ver, si es posible una reinvención a través de la reconfiguración de funciones y espacio de La Tebaida, si bien es una Ciudad que cuenta con problemáticas potentes en su aspecto social y físico (Figura 19 y 20).

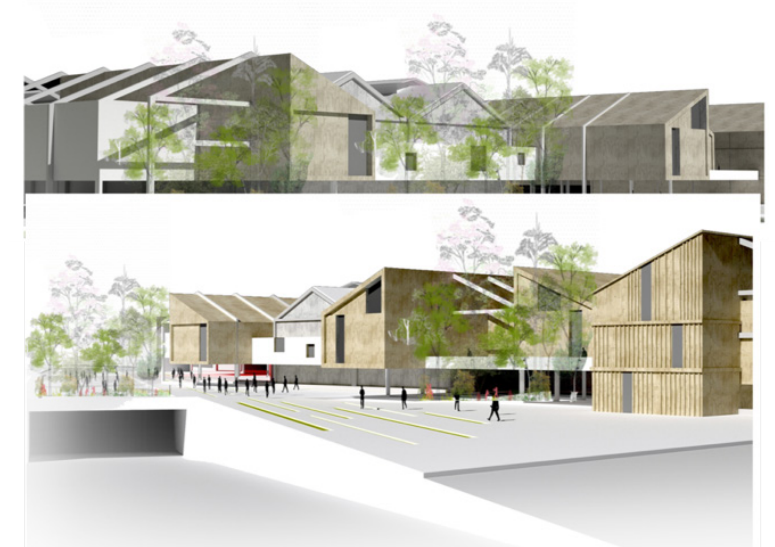

Figura 19. Fábrica Berhlan con nueva configuración espacial, Parasitismo como activador físico social Fuente: Elaboración propia

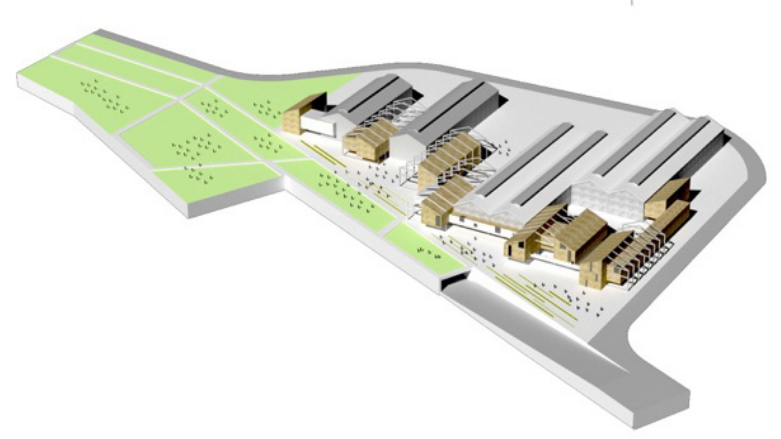

Figura 20. Configuración de Plataforma de Espacio Público como Eje Transversal CiudadFábrica, Soterramiento Vía Panamericana. Fuente: Elaboración propia

\section{CONCLUSIONES}

Los territorios deben ser gestionados de manera integral. La Arquitectura es un eje articulador de los espacios y las comunidades, usando las capacidades y potencialidades para lograr un desarrollo armónico, que tenga concordancia con lo establecido históricamente y con las nuevas tendencias.

El Parasitismo, como eje de impacto, logra establecer una simbiosis espacial, permitiendo una reconfiguración del territorio y un aprovechamiento real de las potencialidades, promoviendo el inicio de una Regeneración Urbana articulada con los nuevos usos y dinámicas socioeconómicas del Municipio.

El emplazamiento de Zonas Industriales tiene impactos sobre el territorio, trayendo discontinuidad urbana, carencia de espacios habitables, caminables, de contemplación, de otros usos del suelo y de relaciones sociales (incluyendo la comercial) y culturales.

La vida urbana en este espacio se reactiva, gracias a la transformación de Fábricas monofuncionales y con infraestructura para un único servicio; y

a Fábricas plurifuncionales y con infraestructura para diversos servicios, con la capacidad de generar Espacios Urbanos adecuados.

La baja percepción de competitividad y de desarrollo del Municipio, debido a la baja articulación con las dinámicas socioeconómicas, ambientales y culturales de su entorno nacional y regional, son derivadas de un uso inadecuado de los espacios con potencialidades como el de la Zona Industrial. 


\section{REFERENCIAS}

Batty M. (2012). Urban regeneration as self organisation. Editor Littlefield, London regeneration. (pp. 54-57). Londres: guest-edited by David Littlefield.

Bohigas, O. (2004). La Ciudad un lugar. Editorial Electa, Contra la incontinencia urbana reconsideración moral de la Arquitectura y la Ciudad. (pp. 224). Madrid, España.

Furbey, R.; Macey, M. (2005). Religion and urban regeneration: a place for faith?. Policy \& Politics, 33(1), 95-116.

Gobernación del Quindío. (2011). Plan regional de competitividad 2032. Pag. 11,14 y 15.

Jones, P., Evans, J. (2013). Urban regeneration in the UK: Boom, bust and recovery. ed no 2. Londres, Reino Unido: Sage Publications Ltd. Disponible en: https://books.google.com.co/books?hl=es\&lr=\&id=YmiuqqOXPMC\&oi=fnd \&pg $=P P 1 \& d q=$ Jones $+y+$ Evnas $+(2013 \&$ ots $=$ QIUM7NHOFm \&sig $=C$ VZ9TZKyP2M7KKVzvyVNq8Y-qU\&redir esc=y\#v=onepage \&q=Jones\%20y\%20Evnas\%20 $\underline{(2013 \& \mathrm{f}=\text { false }}$

Ponce, G.; Martínez, F. (2001), Industria y Ciudad entre la aceptación y el rechazo de una relación histórica, vol. 25. Revista investigaciones geográficas, España.

Remesar, A. (2012). Procesos de Regeneración Urbana . Centre de Recerca POLIS. Universitat de Barcelona: Barcelona, España.

Sanchez Acedo,C. (2000), Origen y evolución del Parasitismo. Sdad. Coop. De Artes Gráficas. Zaragoza.

Tolosa Palacios J, Chiaretta A, Lovera H, (2006), El Parasitismo: una asociación interespecífica, Ed no 1. Universidad Nacional de Río Cuarto, Córdoba, Argentina. Disponible en: http://helminto.inta.gob.ar/ Alumnos/El\%20Parasitismo\%20Dres\%20Tolosa\%20Chiaretta\%20y\%20Lovera.pdf 